\title{
Making ERS guidelines relevant and accessible: involving patients and the public
}

The European Respiratory Society (ERS) has been in guideline development for more than a decade. The world-renowned members of its guideline task forces have published $>65$ different documents since 2000 alone, including seminal guidelines on pulmonary rehabilitation, classification of the idiopathic interstitial pneumonias and standardisation of spirometry. One of the most successful guidelines to date being "Standards for the diagnosis and care of COPD patients" in collaboration with the ATS, the editorial of which has been cited more than 1,043 times and is used daily in the decision-making processes of respiratory healthcare professionals worldwide [1].

\section{Why involve patients?}

The most highly respected healthcare professionals in respiratory disease are often involved in developing guidelines and ensuring that the evidence base for decisions and recommendations is scientifically sound. However, the opinion of the end-user, the patient, is not always heard. Patients may have very different perspectives on healthcare processes, priorities and outcomes from those of health professionals. These alternate views can be very important and international experience of patient and public involvement (PPI) in clinical research and guidelines development has been accumulating over the last decade [2-5], and is recognised to enhance the quality of guidelines produced.

Patients can identify issues that may be overlooked by healthcare professionals, highlight areas where the patient's perspective differs from health professionals and ensure that guidelines address key issues of concern to patients. "Empowered patients" want to take control of their conditions and therapy, and thus are crucial to the development of treatment guidelines. Despite lack of empirical evidence on the impact of PPI $[6,7]$, it is clear that the patient/public voice is necessary in a modern society, and it is also being mandated by funding bodies and at the political level.

During its Spring meeting, the ERS Scientific Committee unanimously voted to embrace the concept of PPI in its guideline production in order to improve the quality and relevance of its clinical guidelines, optimise end-user take up, encourage patient organisations to get involved with clinical guidelines and promote their use/implementation, and demonstrate that the ERS are keen to involve patients and public in its activities.

\section{How to involve patients?}

The ERS is in a novel position for a scientific society, as it has a sister organisation, the European Lung Foundation (ELF), which was founded in order to support the ERS by bringing together the public, patients and respiratory professionals; it is therefore
W. Wedzicha ${ }^{1}$

M. Fletcher ${ }^{2}$

P. Powell ${ }^{3}$

${ }^{1}$ ERS Guidelines Director, University College Medical School, Royal Free Campus, University College London, London UK ${ }^{2}$ ELF Chair, and Chief Executive, Education for Health, Warwick UK ${ }^{3}$ ELF Manager, Sheffield, UK

\section{Competing interests} None declared. 
perfectly placed to embark on such an endeavour. The ELF team have been working on finding best practice examples for PPI, with fantastic resources and advice being available from organisations such as National Institute for Health and Clinical Excellence (NICE) [8] and Scottish Intercollegiate Guidelines Network (SIGN) [9]

The methodology for PPI must work for the organisation in question to ensure optimal outcome for those involved, although for all it is key that PPI must be built in and not bolted on and that the expectations of the patient and requirements for the project should be clear at the outset. In order to ensure productive interaction, training and support will need to be given to those taking part before and during interaction with professionals.

\section{The process}

Figure 1 shows a flow diagram of the steps that will be involved in the PPI process for ERS guidelines.

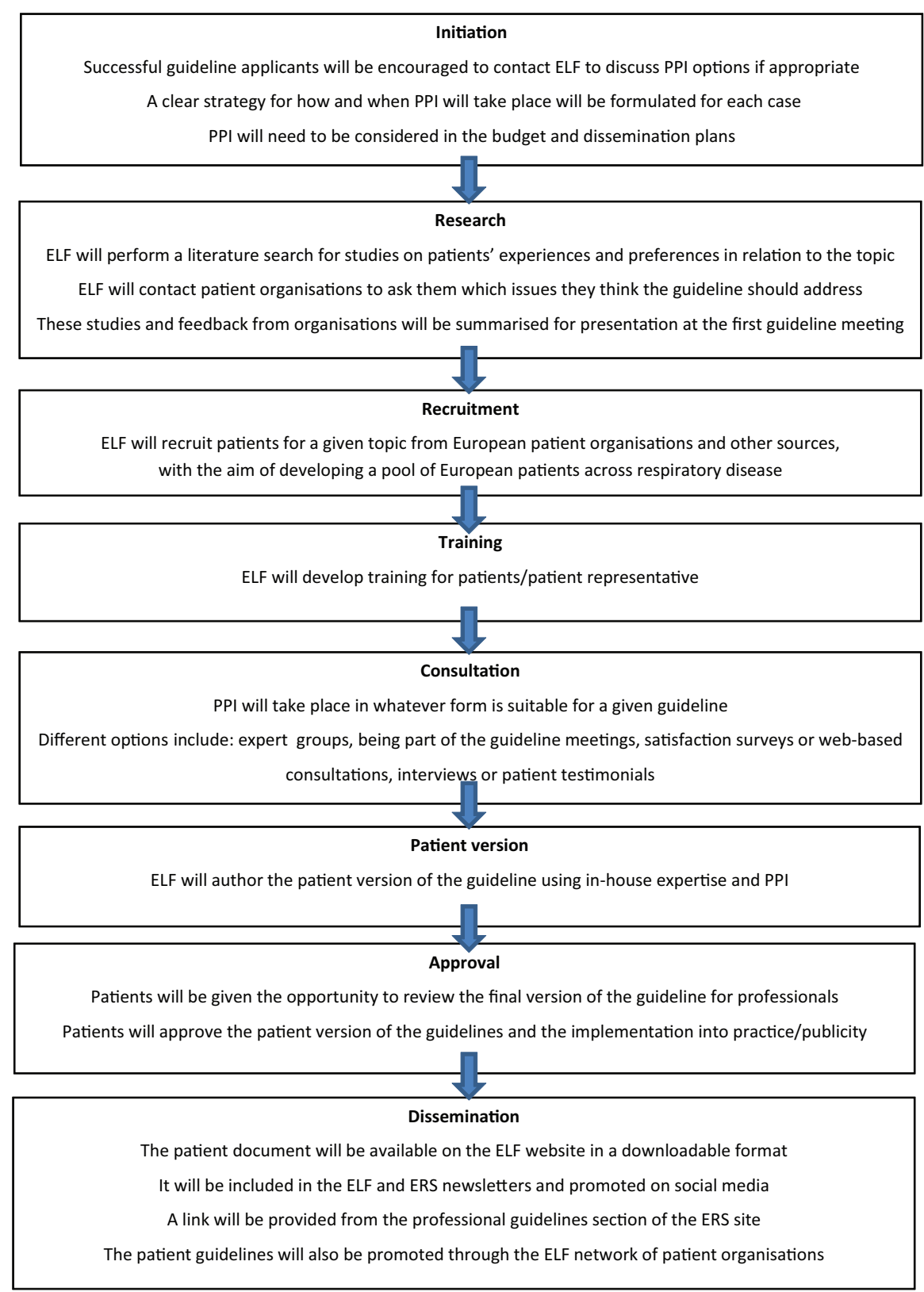

Figure 1

Flow diagram showing the steps involved in patient and public involvement in the creation of ERS guidelines. 


\section{Improving guidelines}

The ERS and the ELF hope that working together will result in more relevant, more appropriate and more understandable guidelines that will be embraced and utilised by professionals and patients, and would encourage any member of an ERS guideline task force to speak to the ELF team about getting patients involved. The ELF would also like to strongly encourage any patient organisation that would be keen to get their opinions and members' voices into daily treatment to also contact Pippa Powell, Manager of the European Lung Foundation, for further information (pippa.powell@europeanlung.org).

\section{References}

1. Celli BR, MacNee W, Agusti A, et al. Standards for the diagnosis and treatment of patients with COPD: a summary of the ATS/ERS position paper. Eur Respir J 2004; 23: 932-946.

2. Schuneman HJ, Fretheim A, Oxman AD. Improving the use of research evidence in guideline development: 10. Integrating values and consumer involvement. Health Res Policy Syst 2006; 4: 22.

3. Krahn M, Naglie G. The next step in guideline development: incorporating patient preferences. JAMA 2008; 300: 436-438.

4. Nilsen ES, Myrhaug HT, Johansen M, et al. Methods of consumer involvement in developing healthcare policy and research, clinical practice guideline and patient information material. Issue 3. Cochrane Database Syst Rev; 2006: CD004563.

5. Boivin A, Green J, van der Meulen, et al. Why consider patient's preferences? A discourse analysis of clinical practice guideline developers. Med Care 2009; 47: 908-915.

6. van de Bovenkamp HM, Trappenburg MJ. Reconsidering patient participation in guideline development. Health Care Anal 2009; 17: 198-216.

7. Boivin A, Currie K, Fervers B, et al. Patient and public involvement in clinical guidelines: international experiences and future perspectives. Qual Saf Health Care 2010; 19: e22.

8. National Institute for Health and Clinical Excellence. www.nice.org.uk

9. Scottish Intercollegiate Guidelines Network. www.sign.ac.uk 